\title{
Exploration of Western Himalayan region for identification of gold nanoparticles synthesizing bacteria.
}

\author{
Rajni Kant Thakur* and Poonam Shirkot \\ Address: Department of biotechnology, Dr. Y.S Parmar University of Horticulture and Forestry, Nauni, Solan, \\ Himachal Pradesh 173230, India \\ Email: rajnithakur136@yahoo.in shirkotp@gmail.com
}

Corresponding author*

\begin{abstract}
The development of eco-friendly methods for the synthesis of nanomaterial shape and size is an important area of research in the field of nanotechnology. In present study an indigenous bacterial strain GPI-1 has been isolated from a local gold mine Khaltunala. It was characterized morphological, biochemically and also by using $16 \mathrm{~S}$ rrna gene technology and was identified as Bacillus flexus GPI-1, the phylogeny of this bacterial strain was determined using various bioinformatics tools viz BLASTn and MEGA 5.0. To achieve maximum invitro gold nanoparticles synthesis various parameters such as $\mathrm{pH}$, incubation temperature, incubation time period and wavelength were optimized as $6.8,37^{\circ} \mathrm{C}, 36 \mathrm{hrs}, 560 \mathrm{~nm}$ respectively. Stable and cubical gold nanoparticles (GNPs) formation with 40-45 nm dimensions were synthesized successfully under invitro conditions upon exposure of gold chloride trihydrates $\left(\mathrm{HAuCl}_{4}\right)$ solution to the supernatant of Bacillus flexus strain GPI-1. These gold nanoparticles have been characterized by Transmission electron microscope, Fourier transform infrared spectroscopy (FTIR). Thus in the present study successful biosynthesis method of stable and cubical gold nanoparticles in the size range of 12-30 nm using this efficient Bacillus flexus GPI-1 strain. Thus in the present study leading to development of an easy bioprocess for synthesis of GNPs of desired size and shape, has been reported and this green route of biosynthesis of GNPs is a simple, economically viable and an eco-friendly process. The use of gold nanoparticles in biomedical research like X-ray computed tomography and magnetic resonance imaging, cancer research, drug delivery applications.
\end{abstract}

\section{Keywords}

Bacillus flexus, Gold nanoparticles, Transmission electron microscope, Fourier transform infrared spectroscopy 


\section{Introduction}

Nanotechnology is a group of emerging technologies in which the structure of matter is controlled at the nanometer scale to produce novel materials and devices that have useful and unique properties. In order to achieve the desired control, a special non-random eutectic environment needs to be available. Although chemical and physical methods may successfully produce pure, well defined nanoparticles, these are quite expensive and potentially dangerous to the environment. As an alternative to toxic and expensive physical methods for nanoparticles fabrication, using microorganisms, plants and algae possess significant potential to synthesize the materials in the nano range and in addition, the toxicity of the by-product would be lesser than the other synthetic methods [1-3]. Physical methods usually require high temperature, vacuum and expensive equipment which makes these techniques uneconomical, whereas chemical methods need different types of toxic and expensive chemicals making nanoparticles production very expensive and hazardous. These disadvantages of both physical and chemical methods for synthesis of nanoparticles greatly limit their applications in various fields and therefore development of reliable, nontoxic and eco-friendly methods for synthesis of nanoparticles are of utmost importance to expand their applications. One of alternatives to achieve this goal is to synthesize the nanoparticles by microorganisms, which leads to another new branch of bionanotechnology. The growing momentum of green nanotechnology, the synthesis of NPs utilizing biological materials could be an improved alternative to toxic chemicals and the expensive physical methods. In general, biological organisms, such as bacteria and fungi [4], plants [5], and algae [6] has been reported for development of eco-friendly and cost-effective approaches [7]. Biosynthesis of nanomaterials has received a significant attention in recent times owing to the use of mild experimental conditions such as temperature and $\mathrm{pH}$. These microorganisms play an important role in remediation of metals through reduction of metal ions and some of these microorganisms can survive and grow even at high metal ion concentrations. These are often exposed to extreme environmental conditions, forcing them to resort to specific defence mechanisms to quell such stresses, including the toxicity of foreign metal ions or metals [8]. The biological agents secrete a large amount of enzymes, which are capable of hydrolyzing metals and thus bring about enzymatic reduction of metals ions [9]. The biomass used for the synthesis of nanoparticles is simpler to handle, gets easily disposed of in the environment and also the downstream processing of the biomass is much easier. The mechanism of 
extracellular synthesis of nanoparticles using microbes is basically found to be nitrate reductase-mediated synthesis [10]. This enzyme nitrate reductase helps in the bioreduction of metal ions and synthesis of nanoparticles. A number of researchers supported nitrate reductase for extracellular synthesis of nanoparticles [11-15]. One of the chief applications of nanotechnology is the use of gold nanoparticles in biomedical research like X-ray computed tomography and magnetic resonance imaging [16], cancer research [17], drug delivery applications [18], and its optical properties for cancer diagnosis and photo thermal therapy. In the present study, an indigenous gold nanoparticle synthesizing bacteria has been isolated from biofilm samples of a local goldmine. This bacterium has been identified as Bacillus flexus strain GPI-1 after morphological, biochemical and molecular characterization by $16 \mathrm{~S}$ rrna gene technology. Extracellular, spherical, monodispersed/small clusters of gold nanoparticles were successfully produced. It is an eco-friendly method for the bacteria mediated synthesis of gold nanoparticles by the reduction of $\mathrm{HAuCl}_{4}$ ions using the broth of Bacillus flexus GPI-1 is reported and the bioreduction process was monitored by the UVvisible spectroscopy at $560 \mathrm{~nm}$. The nanostructure and size of the synthesized gold nanoparticles were characterized by transmission electron microscopy (TEM) and Fourier transformation infrared spectroscopy (FTIR) was used to understand the biomolecules responsible for the biosynthesis.

\section{Material methods}

\section{Isolation and identification of gold nanoparticles and bacteria}

A survey was conducted for selection of various sites of goldmine at Khaltunala, in Solan district of Himachal Pradesh. Forty-three samples in form of water, soil, biofilm, pebbles, stalagmite and rock matting were collected and stored at $4{ }^{\circ} \mathrm{C}$ till further experimentation. Three different culture media viz., Nutrient agar medium, Eosin methylene blue agar medium and Luria bertani medium were investigated for isolation of gold nanoparticles synthesizing bacterial isolates. One gram of soil, pebbles and stalagmite $/ 1.0 \mathrm{ml}$ water and biofilm samples were used for isolation of bacterial isolates through using serial dilution technique. Each of the morphologically distinctive colonies was transferred to fresh broth medium and incubated at $37^{\circ} \mathrm{C}$ for $24 \mathrm{hrs}$. Turbid cultures were streaked on plates of solidified growth medium. Individual colonies were restreaked repeatedly, and the axenic cultures thus obtained were stored at $4^{\circ} \mathrm{C}$. 


\section{Morphological characterization}

All the bacterial isolates obtained in previous step were further studied for various morphological characters. Various morphological colony descriptors of colour, size, optical property and elevation of the colonies and various microscopic characteristics studied were gram reaction, shape and arrangement of cells and spore formation.

\section{Quantitative screening of bacterial isolates for gold nanoparticles synthesis ability}

Assessment of all forty-three bacterial isolates for their ability to synthesize gold nanoparticles was carried out, transferring $1 \%$ of the inoculum (overnight culture) of each bacterial isolate into $50 \mathrm{ml}$ nutrient broth followed by incubation at $37^{\circ} \mathrm{C}$ for $24-48 \mathrm{hrs}$ at 150 rpm. Supernatant of each bacterial culture was collected by centrifugation at $8500 \mathrm{rpm}$ for 15 minutes at $4^{\circ} \mathrm{C}$. Ten $\mathrm{ml}$ of each supernatant was mixed with $10 \mathrm{ml}$ of $1 \mathrm{mM}$ solution of $\left(\mathrm{HAuCl}_{4}\right)$ and incubated at $37^{\circ} \mathrm{C}$ for $240 \mathrm{hrs}$. Formation of gold nanoparticles was monitored from $0-240 \mathrm{hrs}$, with an interval of $12 \mathrm{hrs,}$, which was confirmed by colour change of the solution from light yellow to red wine/purple colour. This formation of gold nanoparticles was also confirmed using spectrophotometer (Spectronic 20, Milton Roy Company) at two different wavelengths of 540 and $560 \mathrm{~nm}$.

\section{Biochemical characterization and molecular characterization}

Eleven bacterial isolates selected were investigated further using various biochemical characters viz beta galactosidase, hydrolysis oxidase, hydrolysis of starch, citrate utilization D-glucose, D- mannitol, fructose, galactose, lactose, maltose, indole production, VogesProskauer reaction, D-mannose, rhamnose using standard assays. DNA extraction from selected bacterial isolates was carried out using genomic DNA extraction Mini kit (Real Genomics). Presence of DNA and its quality was checked using 1.0\% agarose gel and was viewed by UV trans-illuminator. The DNA of GPI-1 strain was selectively amplified using $16 \mathrm{~S}$ rna gene PCR technology. Universal primers B27F (5AGAGTTTGATCCTGGCTCAG-3'U1492R) and (5'-GGTTACCTTGTTACGACTT-3') for 16S rrna gene were used for the experiment and the eluted and purified DNA of GPI-1 was sequenced. The sequence has been submitted to NCBI with accession number KP219454. To gain insight of the evolutionary pattern, phylogenetic tree was constructed using MEGA 5.0 bioinformatics tool. Neighbour-Joining (NJ) technique of mathematical averages (UPGMA) 
was used. Nanoparticles obtained were analysed using various techniques such as, Fourier transform infrared spectroscopy (FTIR and Transmission electron microscope.

\section{Optimization of culture conditions for maximum gold nanoparticles synthesis by selected bacterial isolate}

The culture conditions for useful and prized microorganisms are generally optimized to obtain higher yields of their useful products. In the present study the selected bacterial isolate strain GPI-1 was investigated to study the effect of different parameters of culture conditions such as incubation time, temperature, $\mathrm{pH}$ and wavelength for maximum gold nanoparticles synthesis.

\section{Effect of incubation time}

Effects of different incubation times were ranging from 0-72 hrs for maximum gold nanoparticles synthesis investigated, and the optimum incubation time leading to maximum gold nanoparticles production of gold nanoparticles was selected for further experiments.

\section{Effect of incubation temperature}

Effect of incubation temperature for maximum gold nanoparticles synthesis was studied at a temperature range of $10-50^{\circ} \mathrm{C}$ using nutrient broth optimum incubation time. The optimum temperature leading to maximum gold nanoparticles production of gold nanoparticles was selected for further experiments.

\section{Effect of $\mathbf{p H}$}

Assessment of optimum $\mathrm{pH}$ for maximum gold nanoparticles synthesis by selected bacterial isolate, and $\mathrm{pH}$ range of 5.0-7.5 was examined using nutrient broth medium at an optimum temperature and optimum time. The best condition leading to maximum gold nanoparticles production of gold nanoparticles was selected for further experiments.

\section{Effect of wavelength}

Effects of different wavelength for the maximum values of gold nanoparticles synthesis were assessed ranging from 400-650 $\mathrm{nm}$. The optimum wavelength leading to maximum readings of gold nanoparticles synthesis was selected for further experiments. 


\section{Fourier Transform Infrared Spectroscopy}

This technique was used to study different biomolecules which were involved in biosynthesis of gold nanoparticles. Microcup was washed with $100 \%$ absolute ethanol.

$10 \mathrm{ul}$ sample was filled in a $2 \mathrm{~mm}$ internal diameter microcup and loaded onto the FTIR set at $26^{\circ} \mathrm{C} \pm 1^{\circ} \mathrm{C}$. The samples were scanned in the range of 4,000 to $400 \mathrm{~cm}^{-1}$ using a Fourier transform infrared spectrometer (Thermo Nicolet Model 6700, Waltham, MA, USA). The spectral data obtained were compared with the reference chart to identify the functional groups present in the sample.

\section{Transmission electron microscope}

TEM studies were carried out to study different shapes and sizes of nanoparticles,using Jeol 2100 microscope operating at $120 \mathrm{kV}$ accelerating voltage. Samples were prepared by placing a drop of invitro synthesis gold nanoparticles solutions on carbon-coated TEM grids. The films on the TEM grids were allowed to dry for $5 \mathrm{~min}$ at room temperature before analysis.

\section{Results and Discussion}

Pure colonies were isolated from pebble sample were characterized for their morphological and physiological characteristics by various biochemical tests using the Bergeys Manual of Determinative Bacteriology [20] as summarized in (Table 1). Bacillus flexus GPI-1 was found to be gram positive, spore forming, motile, rod shaped and aerobic bacteria. The isolated strain GPI-1 gave positive results for beta galactosidase, hydrolysis oxidase, hydrolysis of starch, citrate utilization and acid production from D-glucose, D- mannitol, fructose, galactose, lactose, maltose. The strain gave negative results indole production, Voges-Proskauer reaction, no acid production from D-mannose, rhamnose (Table1). Molecular characterization was carried out using 16S r DNA-PCR technology. Total genomic DNA of the GPI-1 bacterial isolate was extracted successfully using genomic DNA extraction Mini kit (Real Genomics) and was selectively amplified with universal primers for $16 \mathrm{~S}$ rrna gene followed by agarose gel electrophosis leading to a single clear band. Which was eluted, purified and sequenced. The sequence was submitted to NCBI with accession number Genbank KP219454. BLASTn analysis depicted homology of GPI-1 bacterial isolate with other Bacillus species. To gain insight into evolutionary pattern, phylogenetic tree was constructed using MEGA 5.0 bioinformatic tool [21]. The bootstrap analysis values identified the bacterial isolate GPI-1 as Bacillus flexus (Figure 1), Multiple sequence alignment of 
query nucleotide sequence of maximum gold nanoparticles synthesizing indigenous Bacillus flexus strain GPI-1 was performed with that of the selected nucleotide sequences using ClustalW program and pairwise percent similarity score of these selected fifteen nucleotide sequences obtained from NCBI database with test isolate GPI-1 from goldmine, elucidates that sequence-1. Bacillus flexus strain GPI-1 showed maximum similarity score of $99 \%$ with Bacterium BW4SW28 (Figure 1).

\section{Characterization of gold nanoparticles synthesized by Bacillus flexus GPI-1}

Addition of gold chloride solution $\left(\mathrm{HAuCl}_{4}\right)$ added into the supernatant of Bacillus flexus GPI-1 changed the colour progressively from light yellow to red at a temperature $37^{\circ} \mathrm{C}$ of predicting formation of gold nanoparticles. The kinetics of reaction was further studied using the spectronic $20 \mathrm{D}$ by recording spectra from colloidal gold solution obtained after, mixing $10 \mathrm{ml}$ of $1 \mathrm{mM}$ gold chloride solution with $10 \mathrm{ml}$ of supernatant of Bacillus flexus GPI-1. The spectra revealed a strong absorption at wavelength of $560 \mathrm{~nm}$ and it increased upto $36 \mathrm{hrs}$ and then decreased. After $36 \mathrm{hrs}$ of incubation, as synthesis of GNPs initiated only after $6 \mathrm{hrs}$ of incubation and showed the presence of GNPs in colloidal solution upto $240 \mathrm{hrs}$ at $37^{\circ} \mathrm{C}$ (figure 2a,b). Size of GNPs was observed through transmission electron microscope and images demonstrating gold nanoparticles possessing the average diameter of $45 \mathrm{~nm}$ as depicted in (figure 3). The fourier transform infrared (FTIR) spectra obtained from the gold chloride solution after interaction with supernatant of Bacillus flexus GPI-1 for 24hrs. The spectra showed the occurrence of three bands at $3500 \mathrm{~cm}^{-1}, 2100 \mathrm{~cm}^{-1} 1980 \mathrm{~cm}^{-1}$ and $1480 \mathrm{~cm}^{-1}$. Peak $3500 \mathrm{~cm}^{-1}$ indicates the presence of carboxylic acids, and N-H primary amines. Peak 2100 $\mathrm{cm}^{-1}$ refers to $\mathrm{C} \equiv \mathrm{C}$ terminal alkynes, peak $1980 \mathrm{~cm}^{-}{ }^{1}$ showed the presence of $\mathrm{C}-\mathrm{N}$ bond, $\mathrm{R}$ $\mathrm{N}=\mathrm{C}=\mathrm{S}$ is specific type of bond, $1480 \mathrm{~cm}^{-1}$ peak indicates the presence of $\mathrm{C}-\mathrm{H}$ bond and confirm that alkyl group is present (figure 4).

\section{In vitro synthesis of gold nanoparticles by indigenous Bacillus flexus strain GPI-1}

Extracellular biosynthesis of gold nanoparticles was carried out using supernatant of Bacillus flexus strain GPI-1, treated with $1 \mathrm{mM}$ gold chloride solution and incubated at $37^{\circ} \mathrm{C}$ for a time period of 0-240 hrs. Biosynthesis absorption spectra of gold nanoparticles which was indicated by colour change of solution from yellow to red wine (Figure 5) and was further confirmed spectrophotometrically. UV-VIS absorption spectra and the time of incubation course and increase in formation of gold nanoparticles took place upto $36 \mathrm{hrs}$ and remained stable upto $48 \mathrm{hrs}$ and then the values declined upto $240 \mathrm{hrs}$. Gold nanoparticles formation 
clearly revealed the gold nanoparticles formation initiated after $6 \mathrm{hrs}$ and studies at two different wavelengths of $540 \mathrm{~nm}$ and $560 \mathrm{~nm}$ (Figure 2a, b). On the basis of data obtained at $540,560 \mathrm{~nm}$ it was quite clear that results obtained at 560nm had a supremacy over $540 \mathrm{~nm}$ results, so $560 \mathrm{~nm}$ wavelength was selected for further experiments. Gold nanoparticles O.D value sharply increases 6 to $36 \mathrm{hrs}$ and then it showed stability upto $48 \mathrm{hrs}$.

\section{Optimization of culture conditions for maximum gold nanoparticles synthesis by}

\section{Bacillus flexus strain GPI-1.}

Traditional optimization has been carried out by monitoring the effect of one factor at a time on an experimental response. While only one parameter is changed, others are kept at a constant level. The bacterial isolate Bacillus flexus GPI-1 depicting maximum gold nanoparticles synthesis activity was further optimized to study the effect of different factors such as incubation time, temperature, $\mathrm{pH}$ and wavelength on gold nanoparticles synthesis. Effect of $\mathrm{pH}$ on biosynthesis of gold nanoparticles by Bacillus flexus GPI-1 bacterial supernatant of was studied for 0-72 hrs using $1 \mathrm{mM}$ gold chloride solution at a $\mathrm{pH}$ range of 5.0, 6.0, 6.8, 7.5, 8.0 (Figure 6a) and it was observed that maximum gold nanoparticles took place at $\mathrm{pH}$ : 6.8. Thus $\mathrm{pH}$ has been found to be an important parameter affecting gold nanoparticles synthesis [22]. Variation in $\mathrm{pH}$ during exposure to gold ions had an impact on the size, shape and number of particles produced per cell [23]. Gold nanoparticles formed at pH 6.8 were predominantly triangles, spherical, hexagons, circular in shape. Whenever $\mathrm{pH}$ increases, more competition occurs between protons and metal ions for negatively charged binding sites. Effects of different incubation times for maximum gold nanoparticles synthesis were investigated from 0-72 hrs. The optimum incubation time of $36 \mathrm{hrs}$, leading to maximum gold nanoparticles production was observed (Figure 6b). Effect of incubation temperature for maximum gold nanoparticles synthesis was studied at a temperature range of $10-50^{\circ} \mathrm{C}$ using nutrient broth and optimum temperature of $37^{\circ} \mathrm{C}$ leading to maximum gold nanoparticles synthesis was observed (Figure 6c). It has also been reported that incubation time for maximum gold nanoparticles formation ranges from 30 to $37^{\circ} \mathrm{C}$ [24]. Effect of different wavelengths for the maximum optical density values of gold nanoparticles synthesis was investigated in the range of 400-650 nm and an optimum wavelength of $560 \mathrm{~nm}$ was found to be leading to maximum values of optical density of gold nanoparticles synthesis (Figure 6d).

\section{Conclusion}


Formation of gold nanoparticles was apparent from the gradual changes in the color of incubated solution from pale yellow to dark purple, but the color of control remained practically unchanged during the entire incubation period. This color changes from pale yellow to dark purple is attributed to surface plasmon resonance. The FTIR measurements were carried out to identify the possible bio-molecules responsible for capping and efficient stabilization of the metal nanoparticles synthesized by Bacillus flexus. The spectrum represents different functional groups of adsorbed. It seems that the FTIR spectrum reveal the presence of different functional groups like there may be presence of carboxylic acids, and N$\mathrm{H}$ primary amines, alkyl group helps in synthesized gold nanoparticles. It is believed that the enzyme nitrate reductase could be responsible for bioreduction of metal ions and synthesis of nanoparticles. The bioreduction of gold ions was found to be initiated by the electron transfer from the NADPH-dependent reductase as a electron carrier. Next, the gold ions $\left(\mathrm{Au}^{+}{ }^{+}\right.$) obtain electrons and are reduced to elemental gold $\left(\mathrm{Au}^{0}\right)$ nanoparticles. The secreted proteins and enzymes in the medium are responsibles not only for synthesis of metallic nanoparticles, but also for stabilization of nanoparticles against aggregation. It has been reported first time that the use of Bacillus flexus could be used for extracellular synthesis for gold nanoparticles. The stability of the nanoparticles solution could be due to secretion of certain reducing enzymes and capping proteins by the bacterium. Extracellular formation of gold nanoparticles would be advantageous from process point of view, since it would eliminate the need to recover the particles formed within the cells.

\section{Authors' contributions}

PS conceptualized and designed experiments and provided technical support and helped in drafting the manuscript. RKT conducted experiments, isolation of bacteria, morphological and molecular characterization, invitro synthesis of gold nanoparticles and characterization using FTIR and TEM and helped in drafting the manuscript both author read and approved the final manuscript.

\section{Author information}

$\mathrm{RKT}$ is a PhD research scholar currently and member of six international and national science societies. PS is a professor of Biotechnology with 30 years' research experience and has published research papers in the journals of international and national repute. 


\section{Acknowledgement}

The authors thank to Dr. C Raman Suri and Dr. Manoj Raje for the technical guidance and Dr. CK Shirkot and Dr. Garish Sahani for their cooperation.

\section{References}

1. Malarkodi, C., Rajeshkumar, S., Paulkumar, K., Gnanajobitha, G., Vanaja, M., Annadurai, G., 2013. Eco-friendly synthesis and characterization of gold nanoparticles using Klebsiella pneumonia. J. Nanostruct. Chem., 3, 301-307.

2. Vanaja, M., Gnanajobitha, G., Paulkumar, K., Rajeshkumar, S., Malarkodi, C., Annadurai, G., 2013. Phytosynthesis of silver nanoparticles by Cissus quadrangularis - influence of physico-chemical factors. J. Nanostruct. Chem. 3(17) $1-8$.

3. Rajeshkumar, S., Malarkodi, C., Vanaja, M., Gnanajobitha, G., Paulkumar, K., Kannan, C., Annadurai, G., 2013. Seaweed-mediated synthesis of gold nanoparticles using Turbinaria conoidesand its characterization. 3:44

4. Malarkodi, C., Annadurai, G., 2013. A novel biological approach on extracellular synthesis and characterization of semiconductor zinc sulphide nanoparticles. Appl. Nanosci. 3 389-395.

5. Gnanajobitha, G., Annadurai, G., Kannan C., 2012. Green synthesis of silver nanoparticle using Elettaria cardamomom and assesment of its antimicrobial activity. Int. J. Pharma Sci. Res. (IJPSR) 3 323-330.

6. Rajeshkumar, S., Kannan, C., Annadurai, G., 2012. Synthesis and characterization of antimicrobial silver nanoparticles using marine brown seaweed Padina tetrastromatica. Drug Invention Today, 4(10), 511-513. 
7. Karthiga, V., Soranam, R., Annadurai , G., 2012. Alpha-mangostin, the major compound from Garcinia mangostanalinn responsible for synthesis of $\mathrm{Ag}$ nanoparticles: its characterization and evaluation studies, Research Journal of Nanoscience and Nanotechnology. 2, 46-57.

8. Ahmad, V., Senapati, V., Khan, M.I., Ramani, V., Sriniwas, V., Sastry, V., 2003. Intracellular synthesis of gold nanoparticles by a novel alkalotolerant actinomycete Rhodococcus species, Nanotechnology. 14 824-828. Rai, M., Yadav, P., Bridge, A., Gade, P., 2009b Myconanotechnology: a new and emerging science. In: Rai MK, Bridge PD (eds) Applied mycology, vol 14. CAB International, New York, pp 258267

9. Kumar, A.S., Ansary, A.A., Ahmad, A., Khan, M.I., 2007. Extracellular biosynthesis of CdSe quantum dots by the fungus, Fusarium Oxysporum, J Biomed Nanotechnol. 3 190-194.

10. Duran, N., Marcato, P.D., Alves, O.L., DeSouza, G., Esposito, E., 2005. Mechanistic aspects of biosynthesis of silver nanoparticles by several Fusarium oxysporum strains, J Nanobiotechnol. 3,1-8.

11. Kumar, S.A., Abyaneh, M.K., Gosavi, S.K., Kulkarni, S.K., Pasricha, R., Ahmad, A., Khan, M.I., 2007b. Nitrate reductase-mediated synthesis of silver nanoparticles from $\mathrm{AgNO}_{3}$, Biotechnol. Lett. 29 439-445.

12. He, S., Guo, Z., Y. Zhang, S. Zhang, J. Wang, N. Gu, Biosynthesis of gold nanoparticles using the bacteria Rhodopseudomonas capsulate, Mater Lett 61 (2007) 3984-3987.

13. A.K. Gade, P. Bonde, A.P. Ingle, P.D. Marcato, N. Duran, M.K. Rai, Exploitation of Aspergillus niger for synthesis of silver nanoparticles, J Biobased Mater Bioenergy. 2(2008) 243-247.

14. A. Ingle, A. Gade, S. Pierrat, C. Sonnichsen, M.K. Rai, Mycosynthesis of silver nanoparticles using the fungus Fusarium acuminatum and its activity against some human pathogenic bacteria, Curr Nanosci. (2008) 4141-144. 
15. C. Alric, J. Taleb, G. Le. Duc, C. Mandon, C. Billotey, A.L. Meur-Herland, T. Brochard, F. Vocanson, M. Janier, P. Perriat, S. Roux, O. Tillement, Gadolinium chelate coated gold nanoparticles as contrast agents for both X-ray computed tomography and magnetic resonance imaging, J. Am. Che. Soc.138 (2008) 59085915

16. W. Cail, T. Gao, H. Hong, J. Sun, Applications of gold nanoparticles in cancer nanotechnology, Nanotechnol. Sci. Appl. 1 (2008) 17-32

17. P. Ghosh, G. Han, M. De, C.K. Kim, V.M. Rotello, Gold nanoparticles in delivery applications, Adv. Drug Deliv. Rev. 60 (2008) 1307-1315.

18. J.G. Holt R.N. Krieg P.H.A. Sneath, J.T. Staley, S.T. Williams, Bergey's Manual of Determinative Bacteriology, 9th edition. Williams and Wilkins, Baltimore; 1994.

19. K. Tamura, D. Peterson, N. Peterson, G. Stecher, M. Nei, S. Kumar, MEGA5: molecular evolutionary genetics analysis using maximum likelihood, evolutionary distance, and maximum parsimony methods, Mol Biol Evol. 28 (2011) 2731-2739.

20. P. Mukherjee, A. Ahmad, D. Mandal, S. Senapati, S.R. Sainkar, M.I. Khan , R. Ramani, R. Parischa, P. Ajaykumar, M. Alam, M. Sastry, R. Kumar, Bioreduction of $\mathrm{AuCl}_{4}$ - ions by the fungus, Verticillium sp. and surface trapping of the gold nanoparticles formed, s Angew Chem Int. Ed.40 (2001) 3585-3588. 
21. K. Kaithresan, S. Manivanan, M.A. Nabeel, B. Dhivya, Studies on silver nanoparticles synthesized by a marine fungus, Penicillium fellutanum isolated from coastel mangrove sediment, Colloides surf B Biointerfaces. 71 (2009) 133.

22. L. Sintubin, W.E. Windt, J. Dick, J. Mast, D.V. Ha, W. Verstarete, N. Boon, Lactic acid bacteria as reducing and capping agent for the fast and efficient production of silver nanoparticles. Appl Microbiol Biotechnol 87 (2009) 741-749.

23. M.F. Lengke, M.E. Fleet, G. Southam, Morphology of gold nanoparticles synthesized filaments cynobacteria from gold (III) chloride complexes, Langmuir 22(6) (2006a) 2780-2787.

List of tables and figures

\begin{tabular}{|l|l|}
\hline \multicolumn{1}{|l|}{$\begin{array}{l}\text { Table: } 1 \text { Biochemical characterizations of Bacillus flexus GPI-1 } \\
\text { Positive tests }\end{array}$} & Indole \\
\hline Hydrolysis of starch & Voges Proskaur \\
\hline Hydrolysis of oxidase & No acid production from \\
\hline Beta galactosidase & D mannose \\
\hline Citrate utilization & Rhamnose \\
\hline Acid production & \\
\hline D- glucose & \\
\hline D-mannitol & \\
\hline Fructose & \\
\hline Galactose & \\
\hline Lactose & \\
\hline Maltose & \\
\hline
\end{tabular}

Table: 1 Biochemical characterizations of Bacillus flexus GPI-1 


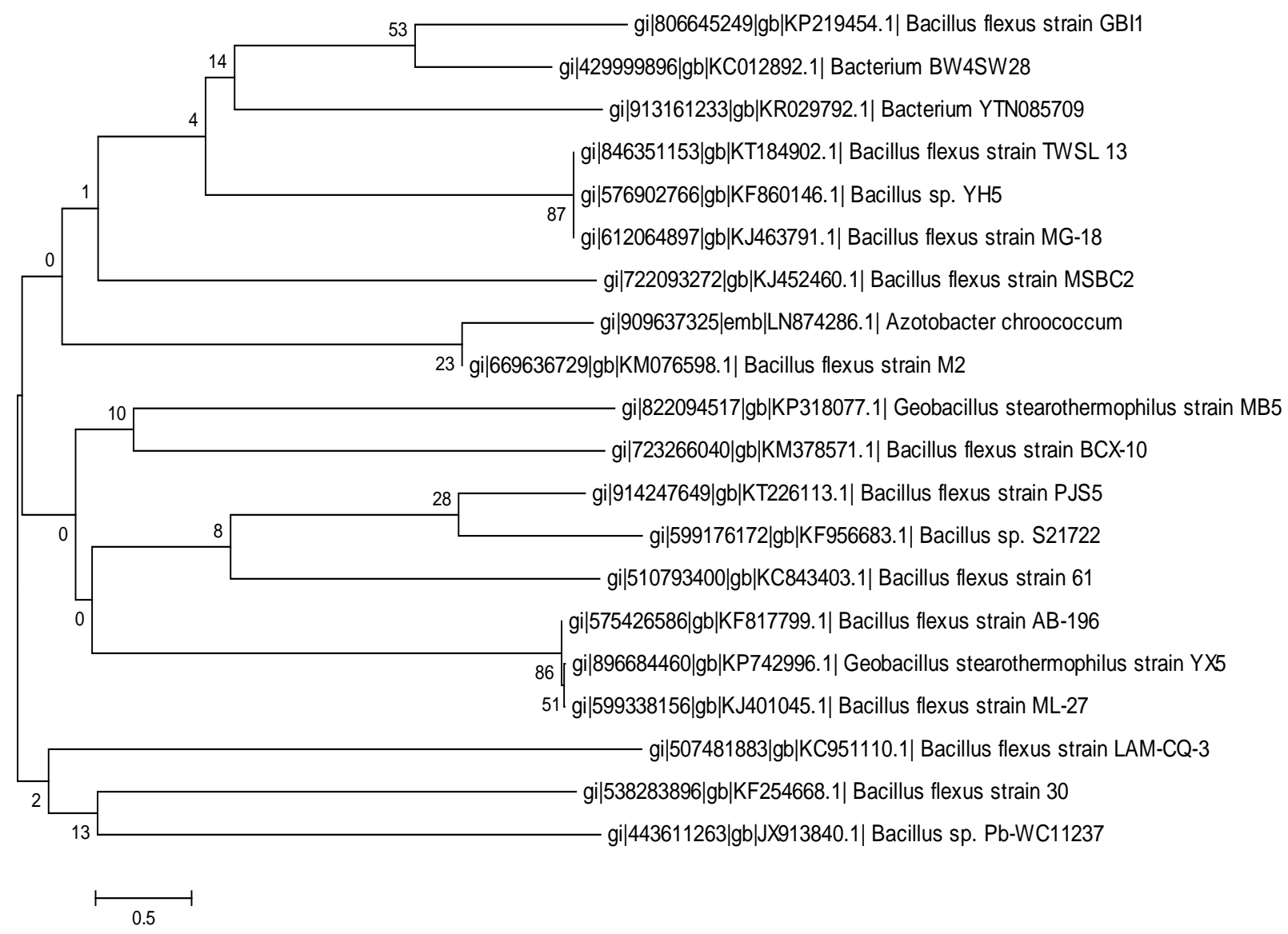

Figure Phylogenetic tree made in MEGA 5.0 software using Neighbor joining method.

Figure: 1 Phylogenetic tree made in MEGA 5.0 software using Neighbor joining method. 


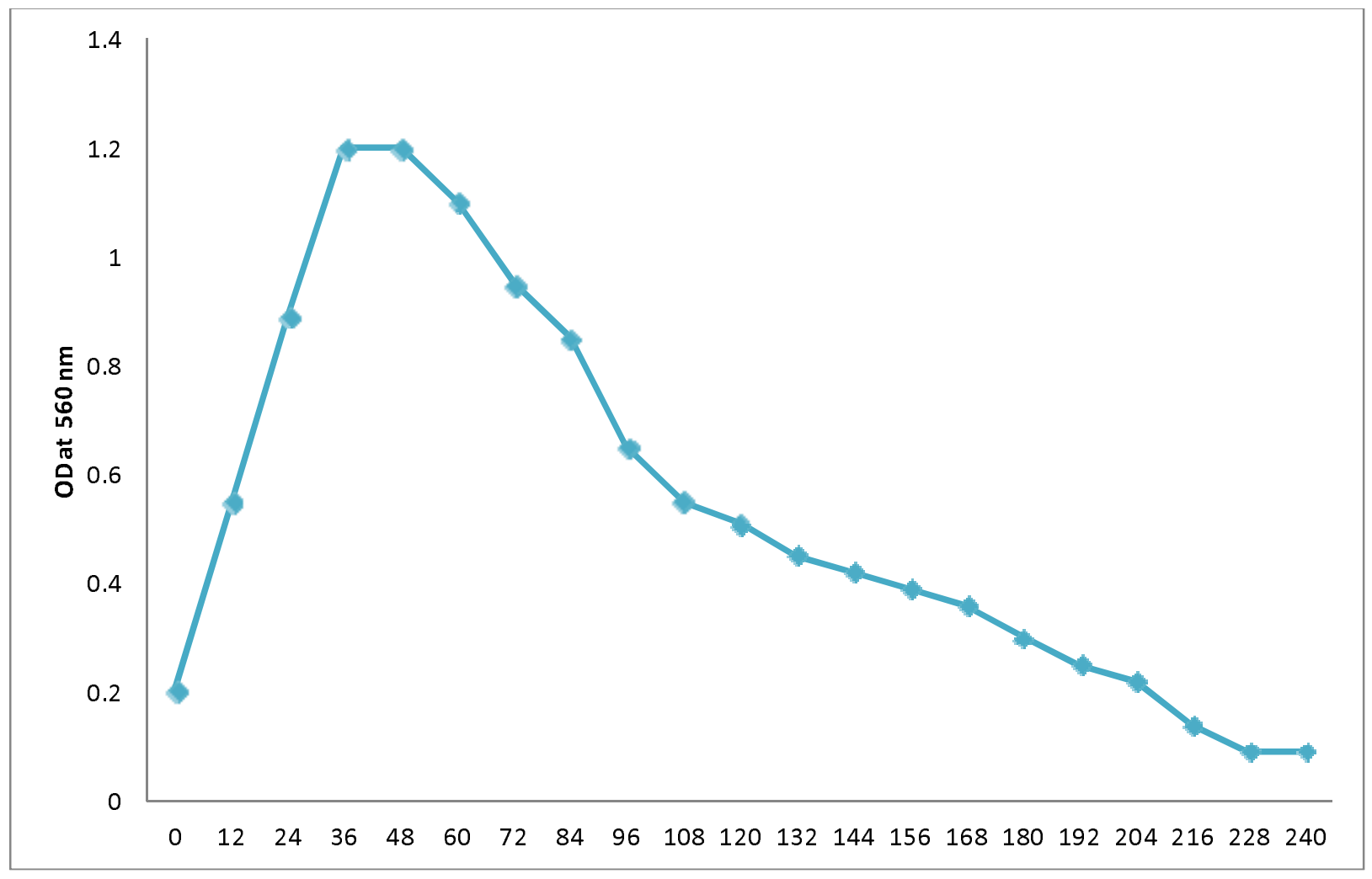

Figure: 2a, UV-Vis absorption spectra of gold nanoparticles after incubation of supernatant of Bacillus flexus GPI-1 with $1 \mathrm{mM}$ sodium chloride for time period (0-240 hrs) at $6.8 \mathrm{pH}$ 


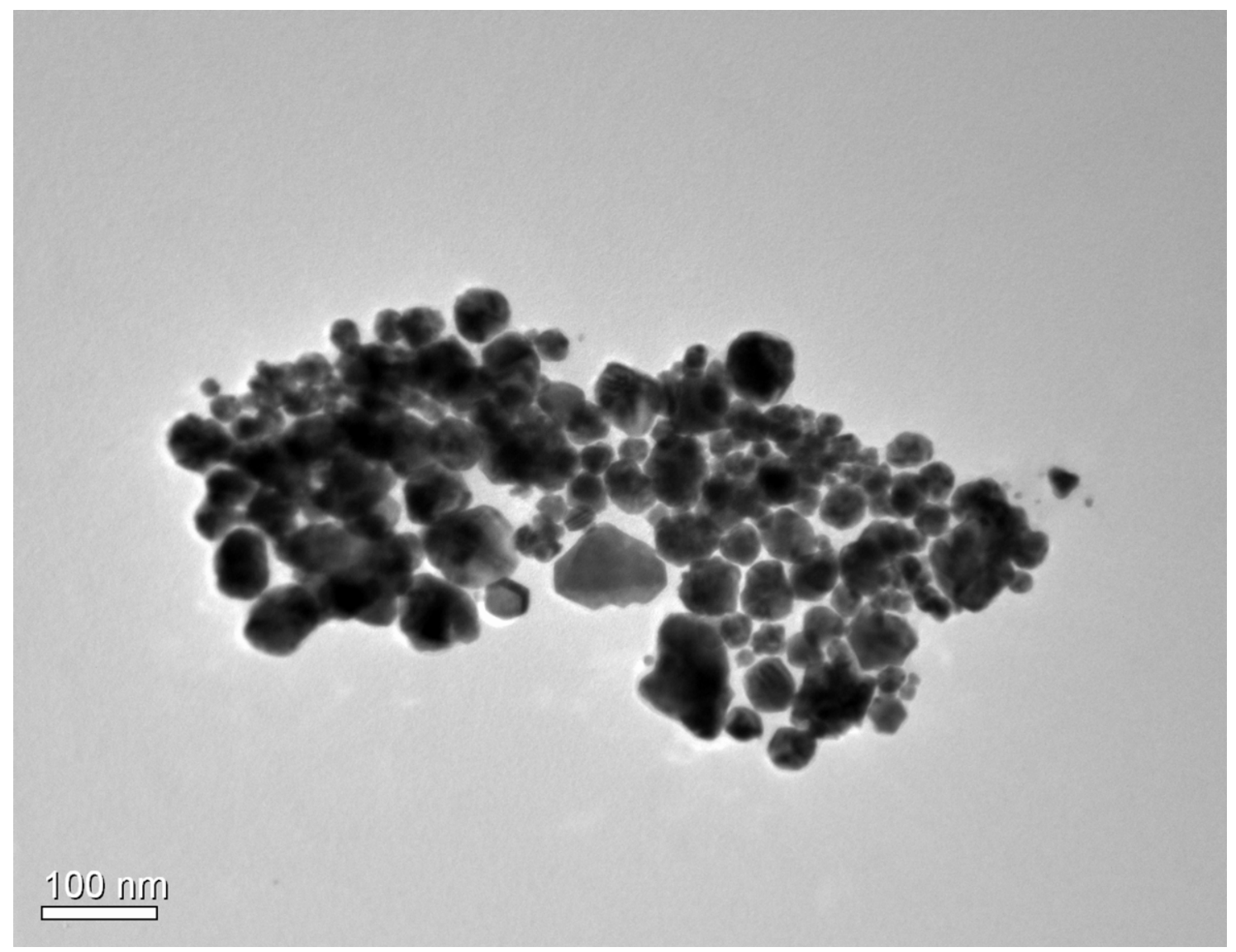

Figure 3: Transmission electron microscope images of indigenous Bacillus flexus GPI-1, showing the different shapes and sizes of nanoparticles. 


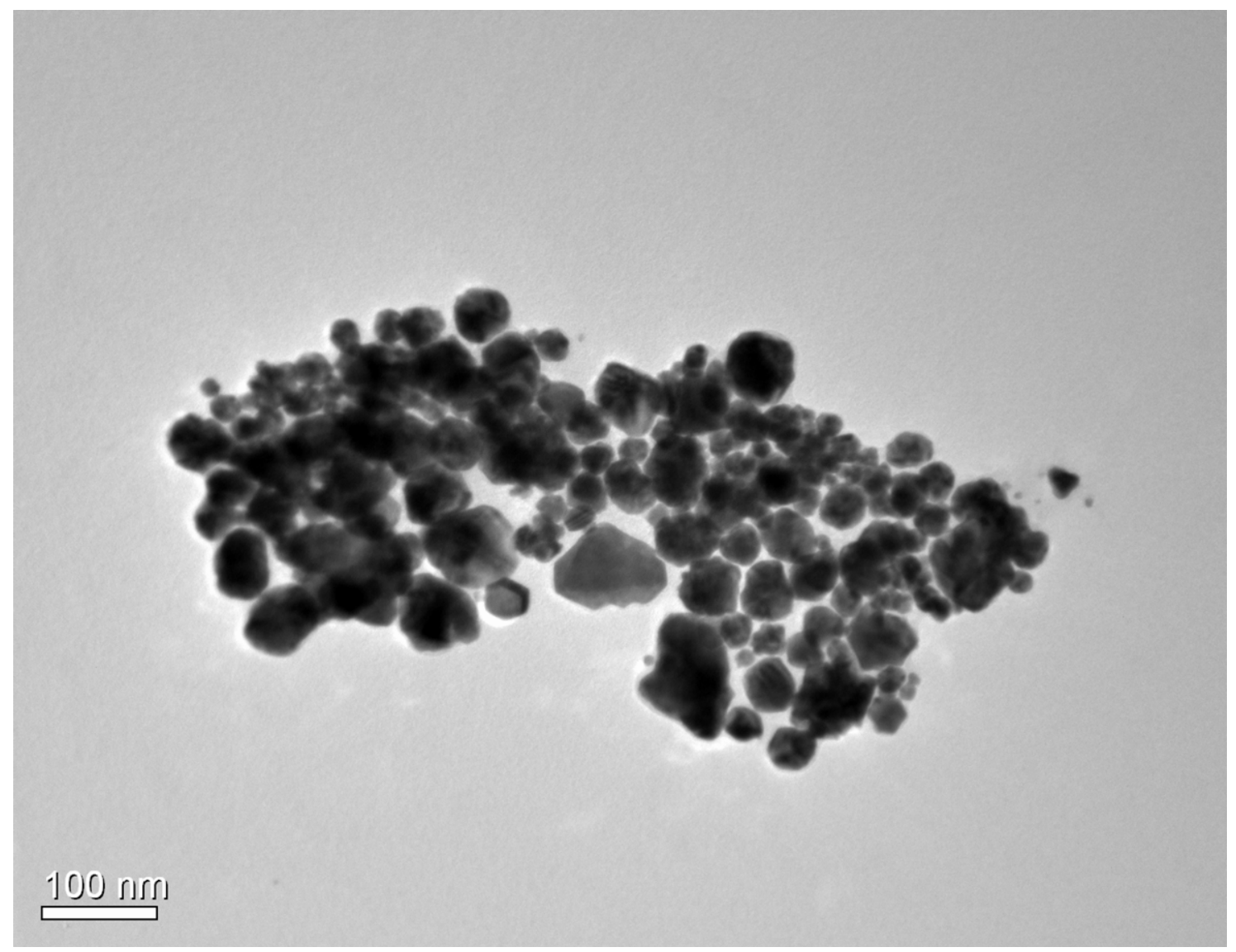

Figure 3: Transmission electron microscope images of indigenous Bacillus flexus GPI-1, showing the different shapes and sizes of nanoparticles. 


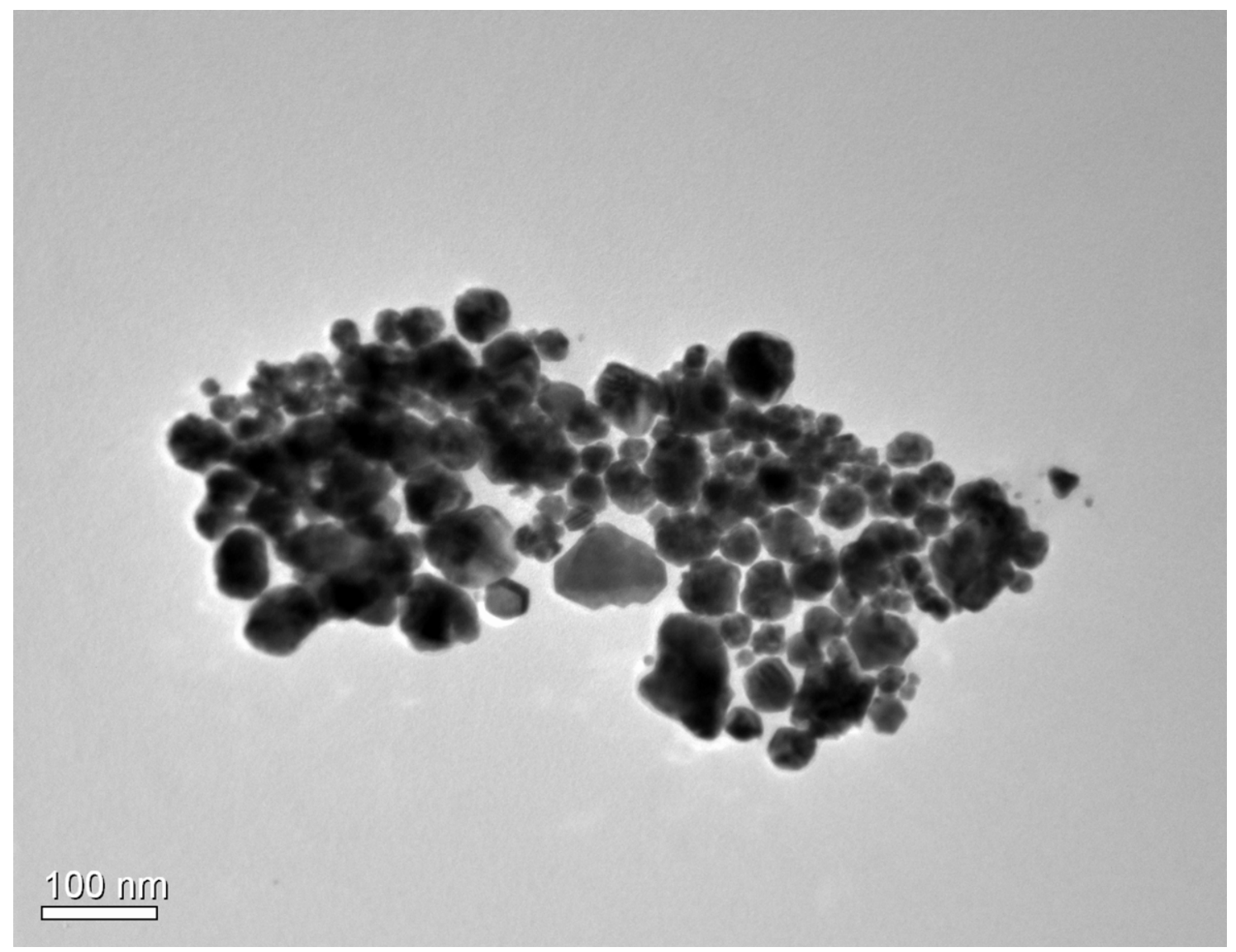

Figure 3: Transmission electron microscope images of indigenous Bacillus flexus GPI-1, showing the different shapes and sizes of nanoparticles. 
bioRxiv preprint doi: https://doi.org/10.1101/164103; this version posted July 15, 2017. The copyright holder for this preprint (which was not certified by peer review) is the author/funder. All rights reserved. No reuse allowed without permission.

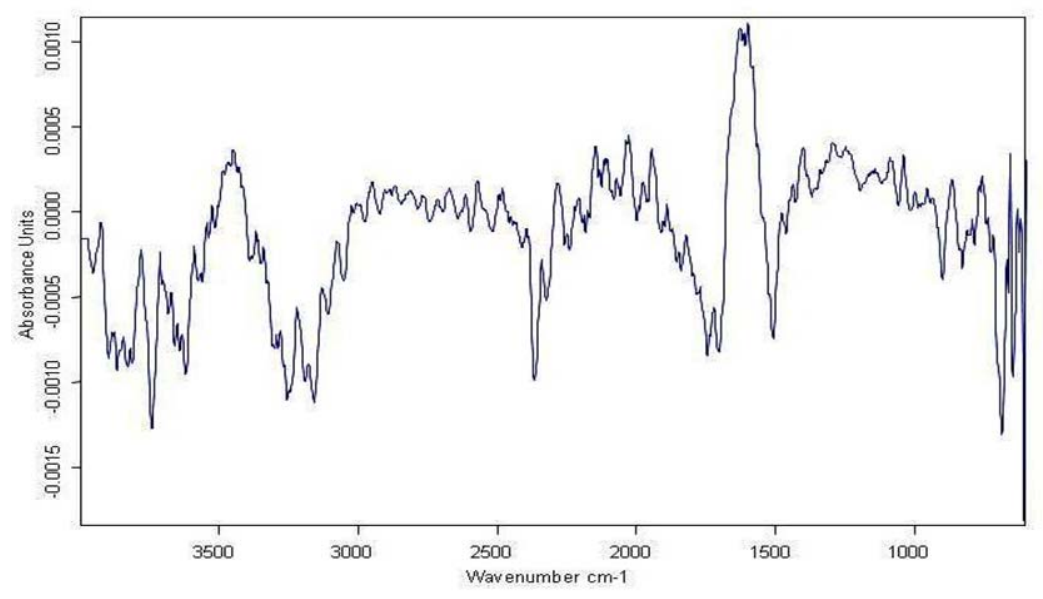

Figure :4 Typical FTIR spectrum of gold nanoparticles generated by Bacillus flexus GPI-1
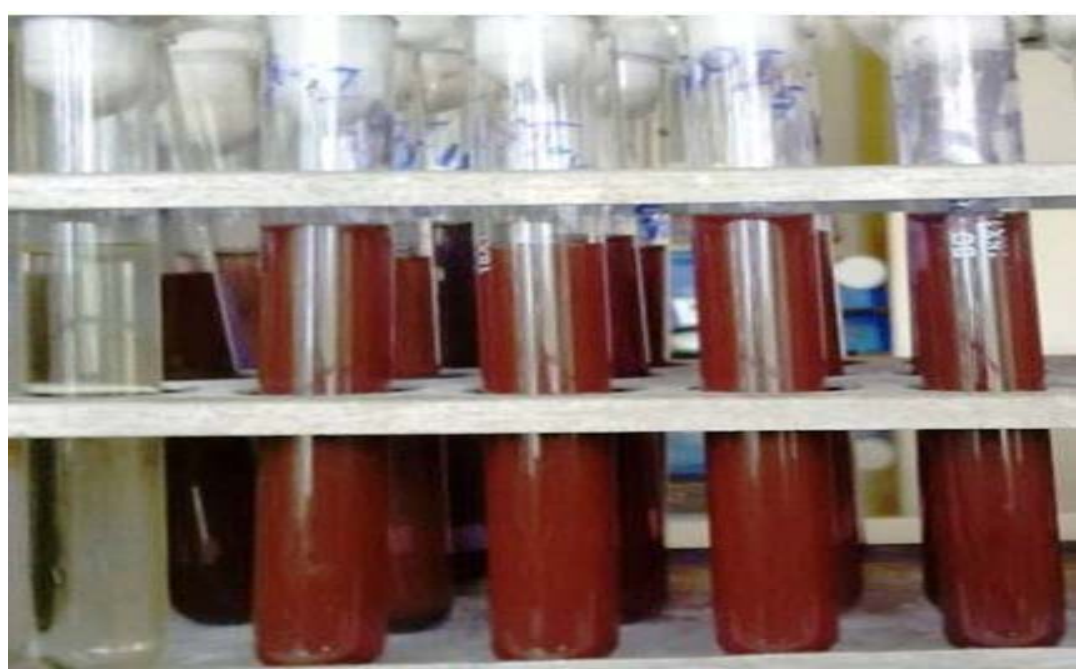

Figure: 5 Synthesis of gold nanoparticlese by Bacillus flexus GPI-1 


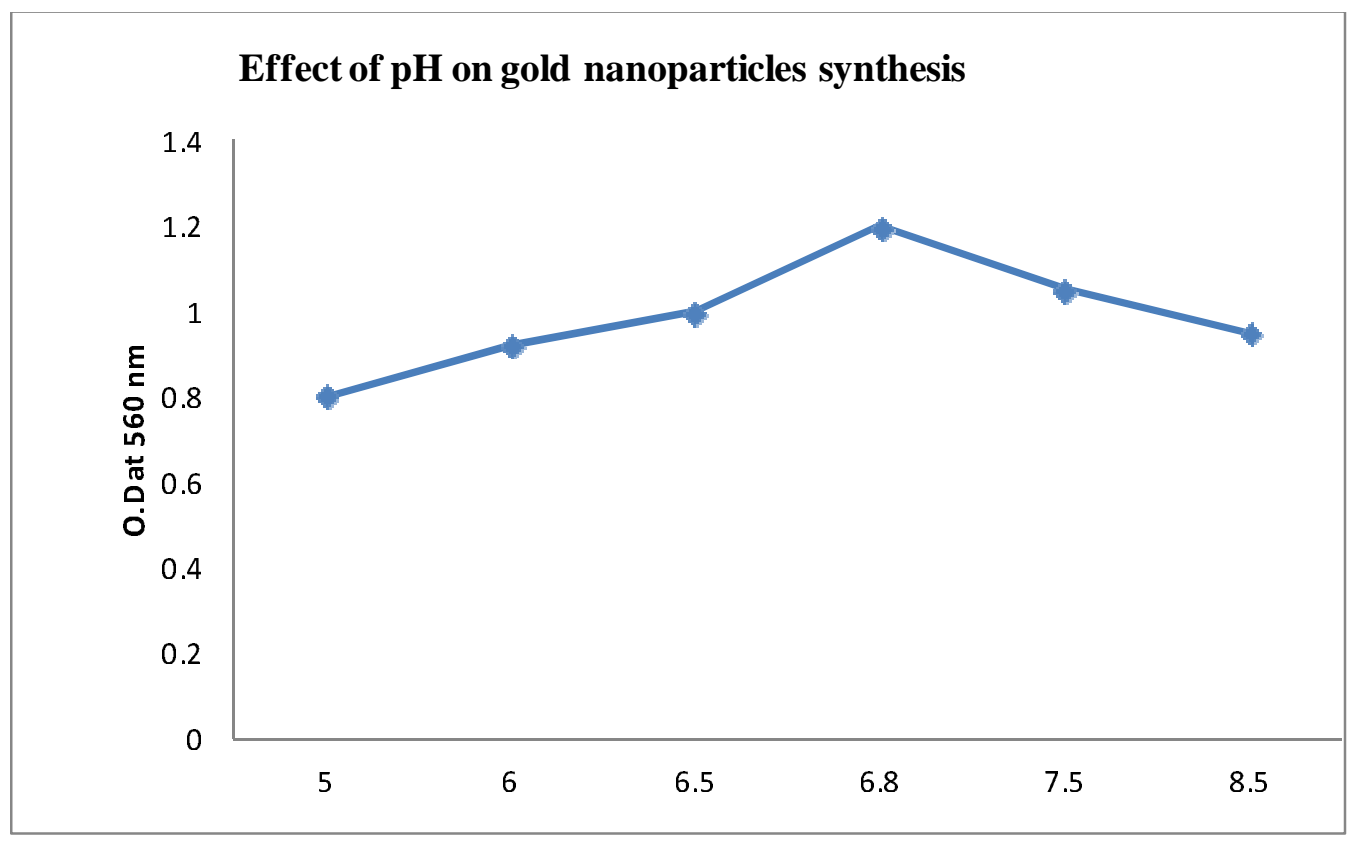

Figure $6 \mathrm{a}$ Effect of $\mathrm{pH}$ on gold nanoparticles synthesis, and it was found that at $6.8 \mathrm{pH}$ maximum GNPs synthesis take place 


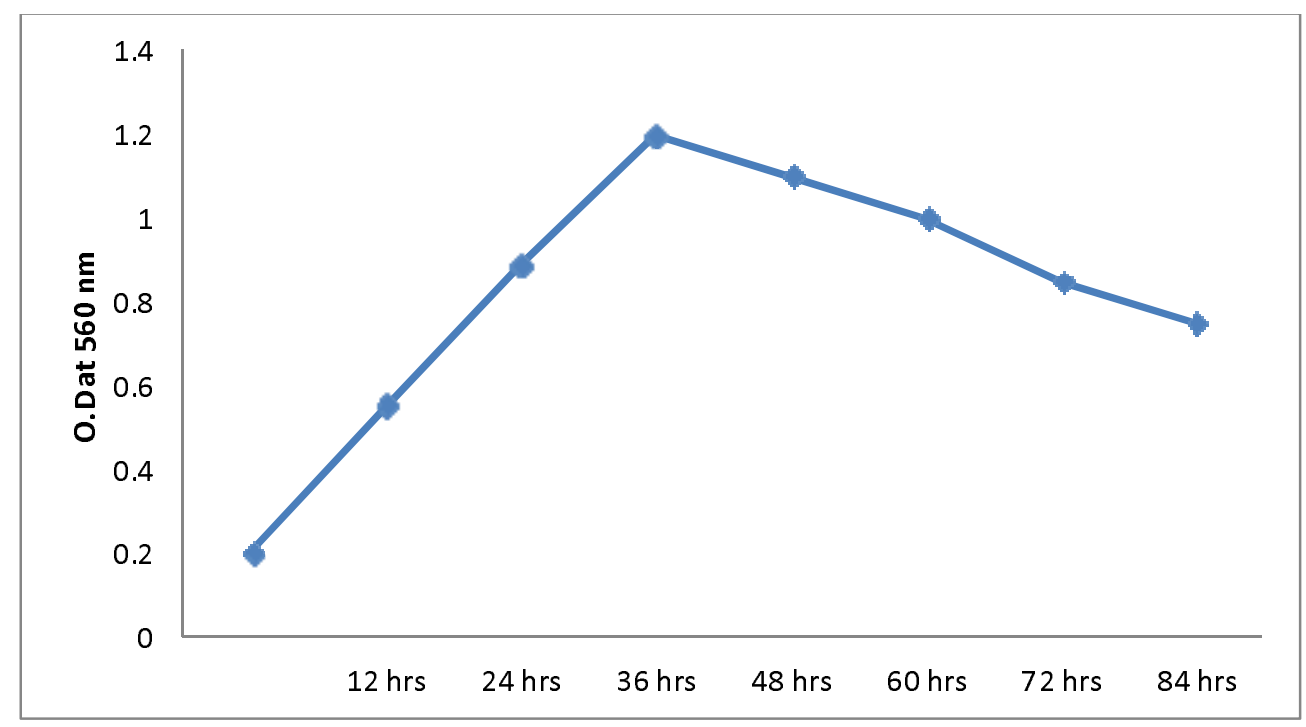

Figure: $6 b$, Effect of incubation time on gold nanopartides synthesis

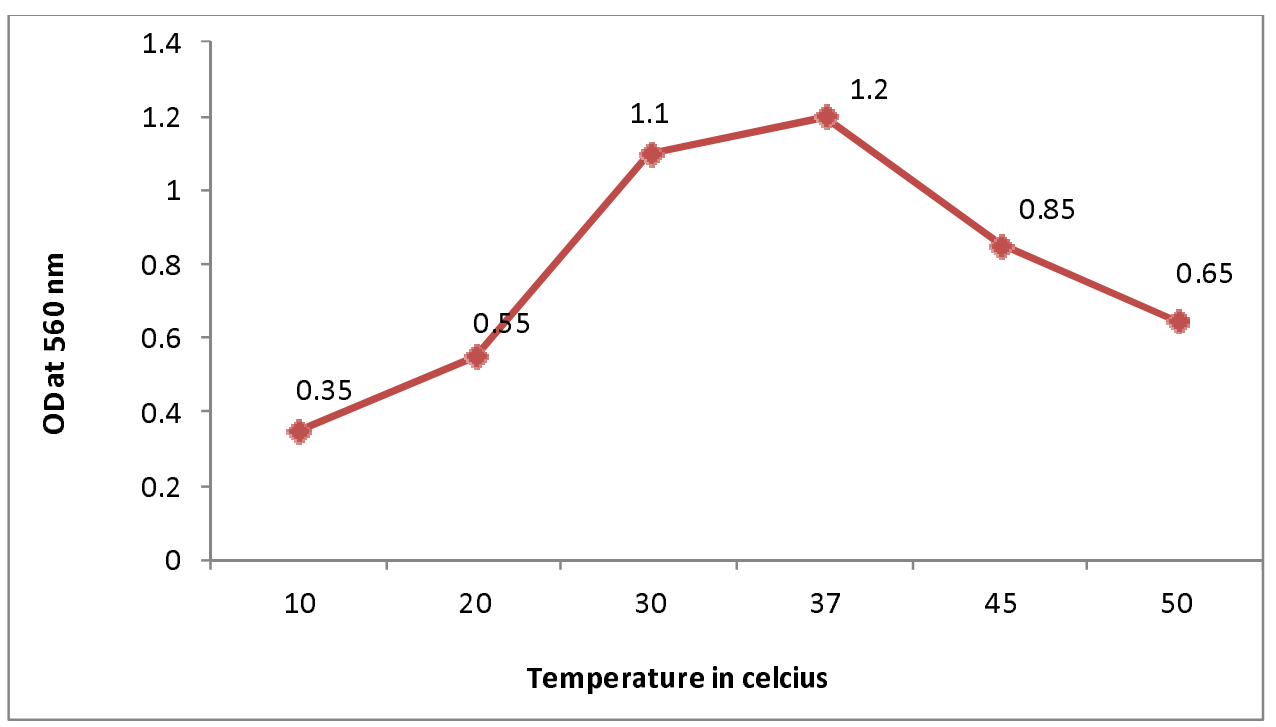

Figure 6c Effect of incubation temperature on gold nanoparticles synthesis 


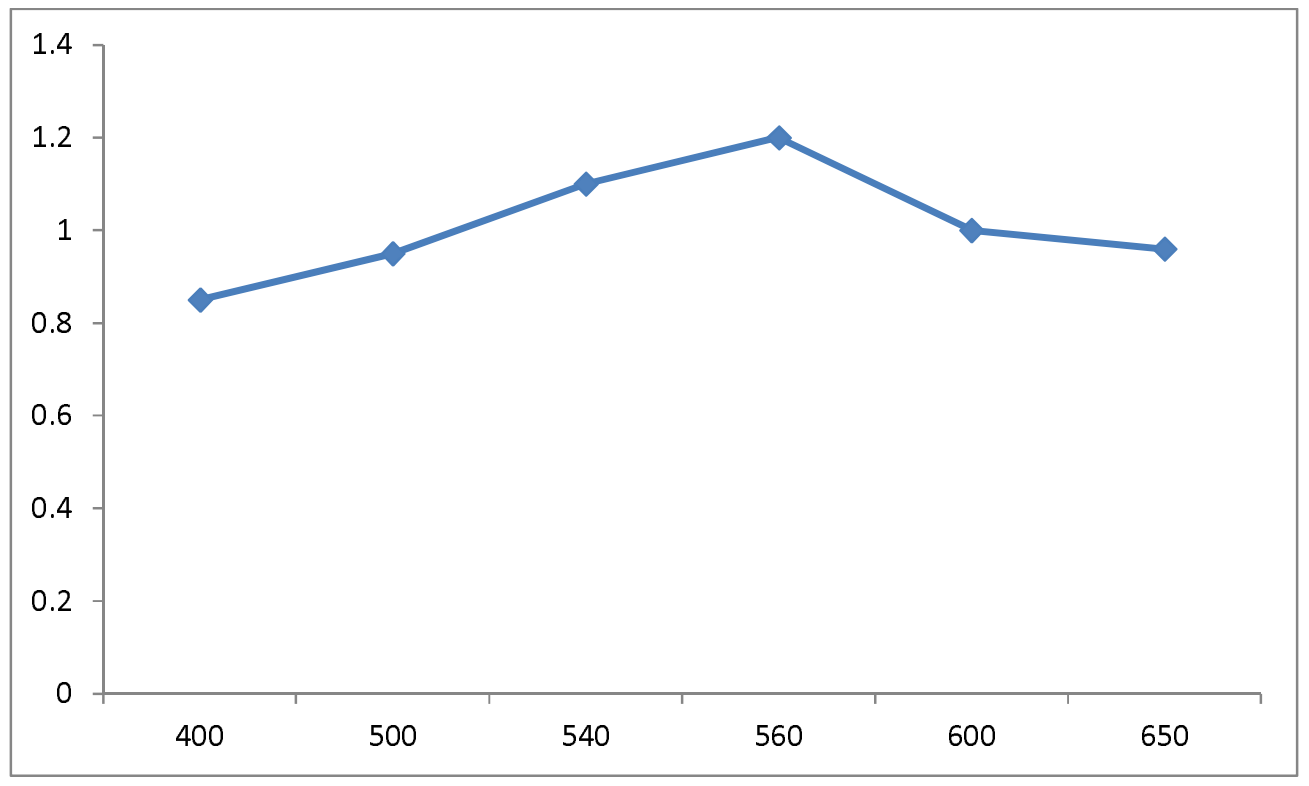

Figure: 6d Effect of different wavelengths on measurement of gold nanoparticles 